\title{
BOUDINAGE: A SOURCE OF STRATIGRAPHIC DISTURBANCE IN GLACIAL ICE IN CENTRAL GREENLAND
}

\author{
By J. Cunningham and E.D. Waddington
}

(Geophysics Program AK-50, University of Washington, Seattle, Washington 98195, U.S.A.)

ABSTRACT. A hydrodynamic model of interface stability in a stratified fluid is reviewed. The model predicts that irregularities on the boundaries of a stiff layer, embedded in a soft matrix, are unstable in pure shearing flow, when compression is normal to the layer. Perturbations on such a layer can grow to form symmetric pinch-and-swell structures called boudins. The model predicts initial perturbation growth rates on the boundaries of an interglacial period ice layer. We find that, beneath an ice divide, irregularities on the Sangamon layer boundaries will not kinematically decay, as the layer thins. Finite-element modelling is used to determine the strain history of Sangamon ice beneath the divide at Summit, Greenland. That history suggests boundary irregularities have grown, relative to layer thickness, at least 26 fold over the past 90000 years. The result may be severe distortion or severing of the layer. Core holes penetrating the layer may recover anomalously thick or thin columns of ice resulting in erroneous environmental and climatic interpretations. Radio echo-sounding may be useful in searching for zones of boudinage, which should be avoided when coring. Initial perturbations might arise from massbalance spatial variations or from transient flow fields.

\section{INTRODUCTION}

Boudinage is a symmetric pinch-and-swell structure found in stratified materials. It forms when a layer of more competent material, embedded in a less competent matrix, is subjected to bednormal compression. Boudinage is common in the geologic record (Ramberg, 1955). Boudin-like structures were observed by Gow (1972) in Antarctic glacial ice. Hambrey and Milnes (1975) discussed the formation of boudins in the margins of Swiss glaciers. Staffelbach and others (1988) suspected boudinage has altered the deep ice stratigraphy at Dye 3, Greenland.

Smith (1975) used hydrodynamic stability theory to derive initial growth rates for boudinage in a layered Newtonian viscous fluid. The model was modified by Smith (1977) to determine initial growth rates in a non-Newtonian fluid. Fullagar (1980) used a vorticity model to describe nucleation of boudinage in a layered Newtonian fluid. Neurath and Smith (1982) further extended Smith's model to include strain softening. This paper reviews Smith and Neurath's work and some of its implications for icecoring programs.

\section{SMITH MODEL}

In a power-law fluid, the relationship between effective stress $t$ and effective strain-rate $\dot{\varepsilon}$ is

$$
\dot{\varepsilon}=A \tau^{n}
$$

where $A$ and $n$ are constants. A non-Newtonian strain-rate softening material has $n$ greater than 1 . The effective viscosity of a power-law fluid is defined

$$
\mu=\tau / 2 \dot{\varepsilon}
$$

Smith $(1975,1977)$ and Neurath and Smith (1982) analyzed the behaviour of a small perturbation on a layer in a block subjected to homogeneous pure shear (Fig. 1). The layer and the

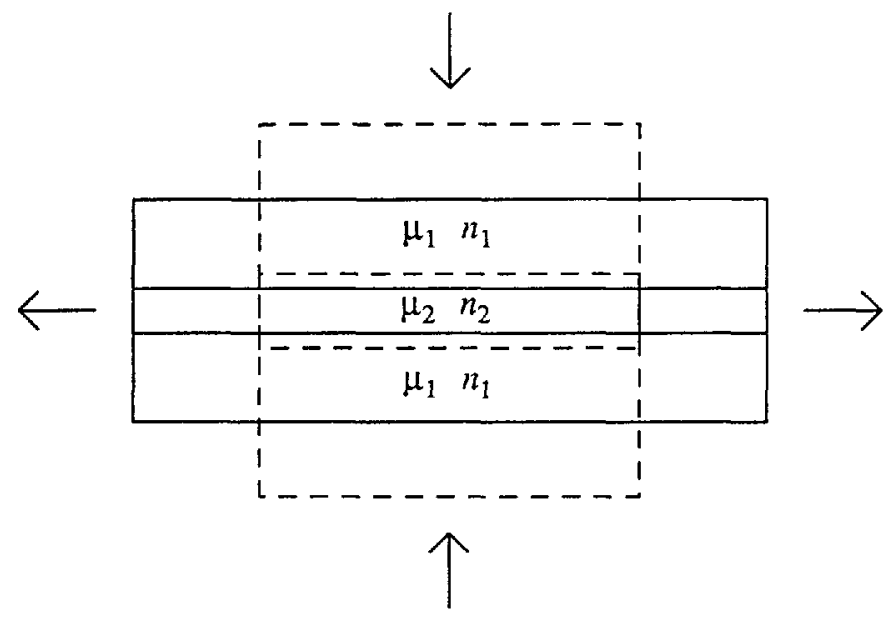

Fig. 1. A layered block undergoing pure shear strain. $n_{1}$ and $n_{2}$ are the power-law exponents and $\mu_{1}$ and $\mu_{2}$ are the effective viscosities of the matrix and the embedded layer, respectively.

surrounding matrix material were anelastic, homogeneous, isotropic incompressible fluids deforming by creep. The rheologic properties of the layer and the surrounding material are described by the effective viscosities $\mu_{2}$ and $\mu_{1}$, and by the power-law exponents $n_{2}$ and $n_{1}$, respectively. They found that, if the effective viscosity ratio $\mu_{2} / \mu_{1}$ is greater than unity and the embedded layer strain-rate softens $\left(n_{2}>1\right)$, interface perturbations grow unstably in pure shearing flow. If the pure shearing flow is oriented such that compression is normal to the embedded layer, interface perturbations will grow into symmetric pinch-and-swell structures called boudins (Fig. 2). Perturbation growth rates increase with (1)

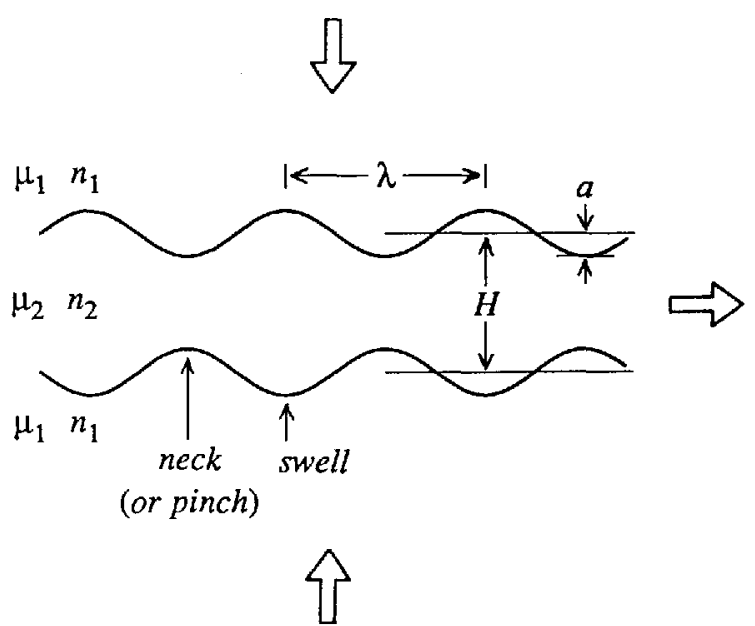

Fig. 2. Idealized flow boudinage. $H$ is the average layer thickness, a is the amplitude, and $\lambda$ is the wavelength of an interface disturbance; $n$ is the power-law exponent and $\mu$ is effective viscosity. 
the effective viscosity ratio, (2) the degree of strain-rate softening of the embedded layer and to a lesser extent by strain-rate softening of the matrix, and (3) strain softening of the embedded layer. Growth rate is also a function of the perturbation wavelength. The dominant wavelength is approximately four times the thickness of the embedded layer.

Initial perturbation is described by the equation

$$
a=a_{0}\left[H_{0} / H\right]^{\gamma}
$$

where $a_{0}$ and $H_{0}$ are the original perturbation amplitude and average layer thickness, $a$ and $H$ are the perturbation amplitude and average layer thickness at a later time, and $\gamma$ is the total normalized growth rate. If $\gamma$ is positive, perturbations grow in an absolute sense and boudinage develops. If $\gamma$ is between negative one and zero, perturbations decay, but not as rapidly as the layer thins. This results in relative growth of perturbations and weak boudin development.

The Smith model applies only to the initial growth of small perturbations. It does not necessarily predict the correct growth rate for large perturbations or strains. To study long-term boudin development, one must resort to physical or numerical models. Neurath and Smith (1982) tested the theoretical model predictions with a series of four wax models. Table I summarizes their results. Without considering strain softening, the theory underpredicted observed growth rates by factors between 2 and 4 . When strain softening was included, the theory correctly predicted observed growth rates in two tests and underpredicted observed growth rates by a factor of 2 in the remaining tests. Even though the theoretical model was derived to describe infinitesimal perturbation growth, these limited tests suggest growth rates do not change dramatically from their initial value, as perturbation amplitudes become finite, or even until the stiff layer is nearly severed. which can be accommodated by extensions to the theory (Neurath and Smith, 1982). The first criterion is satisfied.

In Northern Hemisphere ice caps, the effective viscosity of Holocene ice is 2.5 to 3 times greater than Wisconsin ice (Hooke, 1973; Fisher and Koerner, 1986; Dahl-Jensen and Gundestrup, 1987). It is reasonable to assume that ice from interglacial periods like the Holocene and Sangamon have similar theologic properties, and that ice from glacial periods such as the Wisconsin and Illinoian have similar rheologic properties. This suggests that, in the Northern Hemisphere, Sangamon interglacial period ice has an effective viscosity approximately 3 times that of the surrounding glacial period ice. The second criterion is met.

As a contribution to the Greenland Ice Sheet Project II, we used a variation of the finite-element momentum-balance model developed by Raymond (1983) to estimate the present ice-flow pattern across the crest of the ice divide at Summit, Greenland (lat. $72^{\circ} 17^{\prime} \mathrm{N}$., long. $37^{\circ} 40^{\prime} \mathrm{W}$.) It was found that ice flow off the divide is close to plane strain, suggesting the ice beneath the divide is deforming in two-dimensional pure shear. The third condition is satisfied beneath the Summit divide.

\section{SANGAMON ICE}

A finite-element model of ice flow at Summit indicates that the Sangamon layer was $2400 \mathrm{~m}$ thick 90000 years ago. It is predicted, now, to be $180 \mathrm{~m}$ thick beneath the divide. In this case $H_{0} / H \approx 13$. Given an effective viscosity ratio of 3 and a power-law exponent of 3 for ice, the Smith model (without strain softening) predicts a maximum total normalized growth rate of $\gamma=0$ for boudins. From Equation (3) it can be determined that $a=a_{0}$. Kinematic flattening balances dynamic growth and perturbation amplitudes remain unchanged as the layer thins. This results in relative perturbation growth and weak boudin development.

For example, perturbations that had amplitudes of $1 \%$ of the initial Sangamon layer thickness will, as a result of 13-fold layer thinning, have amplitudes of $13 \%$ of the present layer thickness.

\section{TABLE I. THEORETICAL AND EXPERIMENTALLY OBSERVED GROWTH RATE OF BOUDINAGE IN WAX} MODELS (TABLE ADAPTED FROM NEURATH AND SMITH (1982))

\begin{tabular}{ccccc}
$\begin{array}{c}\text { Model } \\
\text { number }\end{array}$ & $\begin{array}{c}\text { Initial } \\
\text { amplitude }\end{array}$ & $\begin{array}{c}\text { Viscosity } \\
\text { ratio }\end{array}$ & \multicolumn{2}{c}{$\begin{array}{c}\text { Power-low } \\
\text { exponents }\end{array}$} \\
43 & $a_{0} / H_{0}$ & $\mu_{2} / \mu_{1}$ & $n_{1}$ & $n_{2}$ \\
45 & 0.031 & 28 & 1.8 & 5.0 \\
44 & Data missing & 28 & 1.8 & 5.0 \\
46 & 0.044 & 7.3 & 1.8 & 5.0 \\
& 0.063 & 7.3 & 1.8 & 5.0
\end{tabular}

\section{APPLICATION TO ICE}

Staffelbach and others (1988) considered the influence boudinage might have on the ice record at Dye 3, Greenland. They concluded that boudin growth could disrupt small-scale ice stratigraphy, and may be responsible for observed rapid changes in the $\delta^{18} \mathrm{O}$ and $\mathrm{CO}_{2}$ record. We will discuss the implications for large-scale stratigraphic features at Summit, Greenland.

In order to apply Smith's model, a layered material must meet the following criteria:

(1) It must be anelastic, isotropic, homogeneous, and incompressible.

(2) The effective viscosity of the embedded layer must be greater than the effective viscosity of the surrounding matrix.

(3) The material must be subjected to two-dimensional pure shear. (The model is two-dimensional but could be modified to deal with three-dimensional situations.)

Glacial ice is anelastic, homogeneous, and incompressible, but not isotropic. An anisotropic crystal fabric develops as ice deforms. Fabric development is manifested as strain softening,

\section{Predicted growth rates}

$\begin{array}{ccc}\text { Strain-rate } & \text { Strain and strain- } \\ \text { softening } & \text { rate softening } & \begin{array}{c}\text { Observed growth } \\ \text { rates at } H_{0} / H=1.2\end{array}\end{array}$

$\begin{array}{ccc}\gamma & \gamma & \gamma \\ 3.3 & 9 & 8.6 \pm 2.3 \\ 3.3 & 9 & 8.5 \pm 0.7 \\ 1.6 & 4 & 6.7 \pm 0.6 \\ 1.6 & 4 & 7.3 \pm 0.1\end{array}$

Smith (1977) determined that displacing one interface will cause a similar amplitude displacement on the opposite interface. In this case, that would result in necks $26 \%$ narrower than the average layer thickness. Material displaced by necking is moved, by the secondary flow field, into adjacent swells within the layer (Fig. 2). If the perturbations grow as sinusoids, swells would be $26 \%$ thicker than the average layer thickness. At Summit, a core hole penetrating the narrowest part of a neck would encounter $130 \mathrm{~m}$ of Sangamon ice. A core hole passing through the thickest part of a swell would recover $230 \mathrm{~m}$ of Sangamon ice. If strain softening enhances the boudin growth in ice as dramatically as in wax (Neurath and Smith, 1982), the Sangamon layer could potentially be severed now. There is little prospect of successfully predicting, from a theoretical model, whether a core hole would intersect a neck or a swell, as this depends on the configuration of small perturbations 90000 years ago.

\section{INITIAL PERTURBATIONS ON THE SANGAMON LAYER}

Is the Sangamon layer likely to be seriously distorted by boudinage? To answer this, we must put bounds on the possible initial perturbation amplitudes $a_{0}$ in the Sangamon layer thickness 90000 years ago. We will do this by evaluating layer-thinning mechanisms operating near or on ice divides. 
Finite-element modelling (Raymond, 1983) and analytical modelling (Dahl-Jensen, 1989) suggest that ice descends more slowly at a divide than on the flanks of a divide. Rough calculations suggest that, due to this mechanism, the original Sangamon layer could have been $3 \%$ thinner $\left(a_{0} / H_{0}\right)$ under the divide at Summit compared to flank sites. This thin zone could have become a necking site.

If the divide migrated between a few preferred locations during the Sangamon period, this mechanism could have caused the formation of multiple smaller thin zones in the layer. Each thin zone would have become a necking site.

Near Dye 3, Greenland, Whillans and others (1984) mapped an internal ice-radar reflection over an area of $100 \mathrm{~km}^{2}$. The reflector was approximately $1000 \mathrm{~m}$ beneath the surface. It is believed that such internal reflections represent isochrons (Paterson, 1981, p. 75). The surface of the ice sheet is also an isochron. Therefore, the layer above the reflector represents a constant time interval. On this basis, we will use the layer above the reflector as an analogue for the original Sangamon layer. The $1000 \mathrm{~m}$ thick layer contains two variable thin zones, crossing the mapped area, nearly normal to the direction of ice flow. The layer is between 1.7 and $3.8 \%$ thinner than average in one zone and between 1.2 and $5.2 \%$ thinner than average in the other zone. These zones are created when ice flows over bedrock highs. As long as the ice flow is steady, the thin zones will be stationary relative to bedrock, forming a standing wave. If the ice divide were to migrate such that the flow direction reversed, the old standing waves would be out of phase with the new flow. This could generate transient thickness variations that would move with the ice and become necking sites.

Wind-scouring along a stationary divide is another mechanism that can cause localized layer thinning. Fisher and others (1983) determined that winter wind-scouring reduced the annual accumulation at the Agassiz Ice Cap divide by approximately $35 \%$ relative to sites $1 \mathrm{~km}$ away on the lee flank. Reeh and others (1977) collected annual accumulation information at five sites near Dye 3 . Their data show $25 \%$ less accumulation at the divide than on the eastern flank of the divide. Fisher and others (1983) believed this was, in part, due to winter wind-scouring. There is not a pronounced wind-scour signal in the annual accumulation data (unpublished data of J. Bolzan, 1988) near Summit. But data are so sparse that wind-scouring amounting to several per cent of annual accumulation could go undetected. We can conclude only that accumulation rates do vary now near ice divides, and variations of a few per cent or more over distances of several ice thicknesses cannot be ruled out by the data. The situation in Sangamon time is even more uncertain. Once again, if the divide migrated between several preferred sites, several thin zones of lesser amplitude would have formed.

All of these mechanisms are capable of producing one or more thin zones that would become necking sites when subjected to pure shearing flow.

\section{DISCUSSION}

Glacier ice strain softens (Paterson, 1981). We have not yet quantitatively accounted for this effect. A rough calculation (Neurath and Smith, 1982) suggests strain softening will increase the effective flow-law exponent $n_{2}$, resulting in an increase of the total normalized growth rate $\gamma$, for the Sangamon layer, from 0 to between 1 and 2. From Equation (3), this leads to an increase in perturbation amplitudes by as much as 170 .

Ice beneath a divide is straining in pure shear. If the divide were to migrate, that ice would be subjected to a simple shear component superimposed on the pure shear regime. One consequence would be the rotation of existing boudins into the plane normal to the axis of maximum compression (Smith, 1975). Introduction of a large simple-shear component will tend to linearize the flow law for the stress perturbations responsible for boudin growth (Paterson, 1981, p.33). This reduction of the effective power-law exponent will lead to a lower boudin growth rate.

Smith's analysis assumed a sharp interface between the layer and the surrounding matrix. In an ice cap, layer boundaries may not be sharp. Balancing the forces across the interface shows the driving force of perturbation growth depends only on the bulk properties of each layer and the interface slope, not on the thickness of the interface. Finite boundary thickness does not alter growth rates as long as it is a small fraction of the total layer thickness.

The geologic record reveals a spectrum of forms that boudins may take (Ramberg, 1955). On one end of the spectrum is fracture boudinage. This occurs when the strain-rate is high and the embedded layer is brittle. There is no necking or swelling; instead, the layer breaks up into a line of sharp-cornered blocks. The other end of the spectrum is flow boudinage. This occurs when the strain-rate is low and the embedded layer is ductile. Interface perturbations grow in a smooth sinusoidal fashion. Given the low strain-rate of ice beneath a divide and the ductile behaviour of deeply buried ice at such strain-rates, we believe that glacial ice would develop flow boudinage (Fig. 2).

\section{CONCLUSIONS}

We have applied Smith's hydrodynamic stability model to the Sangamon interglacial period ice layer beneath Summit, Greenland. The model indicates that perturbations along the layer boundaries will not decay kinematically. Due to stress concentration and strain-rate softening in necks, dynamic growth balances kinematic flattening. This balance results in relative growth of interface irregularities as the layer thins. Inclusion of strainsoftening effects in the model would probably lead to predictions of absolute perturbation growth and therefore more severe layer deformation and possibly layer break-up.

We cannot eliminate the possiblity that a core hole drilled at the ice divide at Summit, Greenland, may encounter a distorted Sangamon interglacial layer. If a bore hole penetrates a neck, it will encounter an anomalously thin section of Sangamon ice. If the bore hole pierces a swell, it will recover an anomalously thick section of Sangamon ice. Either of these situations will result in misleading stratigraphic and environmental interpretations of the ice core. Numerical modelling would be useful to determine boudin behaviour near the bed, at large strains, and in simple shear. Modelling alone, however, cannot reveal the stratigraphic pattern under Summit, since that depends on the existence of the initial and unknown perturbations on the Sangamon boundaries. Airborne radio echo-sounding (Hodge, 1990), supplemented by ground-based sounding at Summit, may allow detection of existing Sangamon boudins.

\section{ACKNOWLEDGEMENTS}

We wish to thank W.S.B. Paterson and two anonymous reviewers for their thoughtful comments, S. Hodge and J. Bolzan for data, and B. Noseworthy for editing. This work was supported by U.S. National Science Foundation grant DPP-8613935.

\section{REFERENCES}

Dahl-Jensen, D. 1989. Steady thermomechanical flow along twodimensional flow lines in large grounded ice sheets. J. Geophys. Res., 94(B8), 10,355-10,362.

Dahl-Jensen, D. and N.S. Gundestrup. 1987. Constitutive properties of ice at Dye 3, Greenland. International Association of Hydrological Sciences Publication 170 (Symposium at Vancouver 1987 - The Physical Basis of Ice Sheet Modelling), 31-43.

Emerman, S.H. and D.L. Turcotte. 1984. A back-of-the-envelope approach to boudinage mechanics. Tectonophysics, 110, 333338.

Fisher, D.A. and R.M. Koerner. 1986. On the special rheological properties of ancient microparticle-laden Northern Hemisphere ice as derived from bore-hole and core measurements. $J$. Glaciol., 32(112), 501-510.

Fisher, D.A., R.M. Koerner, W.S.B. Paterson, W. Dansgaard, N. Gundestrup, and N. Reeh. 1983. Effect of wind scouring on climatic records from ice-core oxygen-isotope profiles. Nature, 301(5897), 205-209.

Fullagar, P.K. 1980. Nucleation of folds and boudins in terms of vorticity. Tectonophysics, $65,39-55$.

Gow, A.J. 1972. Glaciological investigations in Antarctica. Antarct. J. U.S., 7(4), 100-101.

Hambrey, M.J. and A.G. Milnes. 1975. Boudinage in glacial ice some examples. J. Glaciol., 14(72), 383-393.

Hodge, S.M., D.L. Wright, J.A. Bradley, R.W. Jacobel, N. Skou, and B. Vaughn. 1990. Determination of the surface and bed topography in central Greenland. J. Glaciol., 36(122), 17-30.

Hooke, R.LeB. 1973. Structure and flow in the margin of the Barnes Ice Cap, Baffin Island, N.W.T., Canada. J. Glaciol., 12(66), 423-438. 
Neurath, C. and R.B. Smith. 1982. The effect of material properties on growth rates of folding and boudinage: experiments with wax models. J. Struct. Geol., 4, 215-229.

Paterson, W.S.B. 1981. The physics of glaciers. Second edition. Oxford, etc., Pergamon Press.

Ramberg, H. 1955. Natural and experimental boudinage and pinch-and-swell structures, J. Geol., 63, 512-526.

Raymond, C.F. 1983. Deformation in the vicinity of ice divides. $J$. Glaciol., 29(103), 357-373.

Reeh, N., H.B. Clausen, N. Gundestrup, S.J. Johnsen, and B. Stauffer. 1977. $\delta\left({ }^{18} \mathrm{O}\right)$ and accumulation rate distribution in the Dye 3 area, south Greenland. International Association of Hydrological Sciences Publication 118 (General Assembly of
Grenoble 1975 - Isotopes and Impurities in Snow and Ice), $177-$ 181.

Smith, R.B. 1975. Unified theory of the onset of folding, boudinage, and mullion structure. Geol. Soc. Am. Bull., 86 1601-1609.

Smith, R.B. 1977. Formation of folds, boudinage, and mullions in non-Newtonian materials. Geol. Soc. Am. Bull., 88, 312-320.

Staffelbach, T., B. Stauffer, and H. Oeschger. 1988. A detailed analysis of the rapid changes in ice-core parameters during the last ice age. Ann. Glaciol., 10, 167-170.

Whillans, I.M., K.C. Jezek, A.R. Drew, and N. Gundestrup. 1984. Ice flow leading to the deep core hole at Dye 3, Greenland. Ann. Glaciol., 5, 185-190. 